\title{
Prognostic significance of positive lymph node number in early cervical cancer
}

\author{
JUNG-WOO PARK and JONG WOON BAE \\ Department of Obstetrics and Gynecology, Dong-A University Hospital, \\ Dong-A University College of Medicine, Busan 602-715, Republic of Korea \\ Received October 23, 2015; Accepted February 9, 2016
}

DOI: $10.3892 / \operatorname{mco} .2016 .837$

\begin{abstract}
The aim of the present study was to investigate whether the number of metastatic lymph nodes (LNs) is an independent prognostic factor for early cervical cancer. The medical records of 163 stage IB-IIA cervical cancer patients, treated with radical hysterectomy with accompanying pelvic and/or para-aortic lymphadenectomy between 1999 and 2007, were retrospectively reviewed. All prognostic factors identified as being significant in the univariate analysis were included in the multivariate analysis using the Cox proportional hazards model. Of the 156 patients included in our analysis, 27 had LN metastasis, of whom 14 patients had 1 positive node and 13 patients had $\geq 2$ positive nodes. The 5 -year overall survival (OS) and progression-free survival (PFS) rates were 92.9 and $87.2 \%$, respectively. In terms of $\mathrm{OS}$, tumour stage $(\mathrm{P}=0.002)$ and the number of positive LNs $(\mathrm{P}=0.021)$ were identified as significant prognostic factors. In terms of $\mathrm{PFS}$, tumour stage $(\mathrm{P}=0.049)$ was identified as a significant prognostic factor. In conclusion, the number of LN metastases is an independent risk factor for poorer survival outcomes in patients with cervical cancer.
\end{abstract}

\section{Introduction}

Cervical cancer is the second most common type of cancer affecting women worldwide (1), and is the main cause of cancer-related mortality in women in developing countries (2). In addition, cervical cancer is the only gynaecological cancer that is clinically staged according to the International

Correspondence to: Dr Jong Woon Bae, Department of Obstetrics and Gynecology, Dong-A University Hospital, Dong-A University College of Medicine, 26 Daeshingongwon-Road, Seo-Gu, Busan 602-715, Republic of Korea

E-mail: jwbae@dau.ac.kr

Abbreviations: CCRT, concurrent chemoradiotherapy; FIGO, International Federation of Gynecology and Obstetrics; LN, lymph node; LVSI, lymphovascular space invasion; OS, overall survival; PFS, progression-free survival; RH, radical hysterectomy; RT, radiotherapy

Key words: early cervical cancer, prognostic factors, lymph nodes number
Federation of Gynecology and Obstetrics (FIGO) classification system (3).

Although surgery is no different following preoperative staging of cervical cancer, postoperative treatment is personalized according to histopathological prognostic factors. Given the impact on the quality of life of the patients, as well as postoperative morbidity, combined treatment with radical hysterectomy $(\mathrm{RH})$ and postoperative radiotherapy (RT) is not recommended and should be avoided whenever possible. Various histopathological factors are known to be associated with survival in patients with cervical cancer, including the size of the tumour, the depth of cervical stromal, parametrial, and lymphovascular space invasion (LVSI), the histological type, lymph node (LN) metastasis, and surgical resection margin (4-10).

These prognostic factors are clearly interconnected and studies have been designed, using multivariate analysis techniques, to statistically identify the most effective combination of these risk factors for determining prognostic outcomes in patients with cervical cancer (6-8).

The management of cervical cancer may be surgical $(\mathrm{RH}$ and systematic LN dissection) or exclusively chemoradiotherapy-based. Survival declines significantly with increasing FIGO clinical stage. Although LN status does not modify the FIGO clinical stage, when LN metastases are present, the 5 -year survival rate has been reported to decrease from 85 to $50 \%$ (11). Therefore, LN status represents the most important prognostic factor, while the effect of the number of LNs removed has yet to be determined.

The aim of this study was to investigate whether the number of metastatic LNs is an independent prognostic factor for early cervical cancer.

\section{Patients and methods}

Patients. The present study included a total of 163 stage IB-IIA cervical cancer patients treated between 1999 and 2007 with RH and accompanying pelvic and/or para-aortic lymphadenectomy.

The medical records of each patient were retrospectively reviewed and 7 patients with insufficient data, including 2 patients whose records lacked a date of recurrence and 5 patients with occult cervical cancer detected following simple hysterectomy, were excluded; the remaining 156 patients formed the study population. 
Treatment. Abdominal type III RH with pelvic lymphadenectomy was the standard surgery.Bilateral salpingo-oophorectomy and para-aortic lymphadenectomy were not always performed. Postoperative adjuvant therapy was considered based on histopathological prognostic factors. Patients with at least one of the three high-risk factors (microscopic parametrial invasion, positive pelvic LNs and positive tumour resection margins) received adjuvant RT or platinum-based concurrent chemoradiotherapy (CCRT), which has been the preferred treatment since the 2000's (12). Patients with at least two of the three intermediate-risk factors (LVSI, stromal invasion of $>1 / 2$ of the cervix or $>$ the outer $1 / 3$, and a largest tumour diameter of $\geq 4 \mathrm{~cm}$ ) received adjuvant $\mathrm{RT}$ alone.

Data collection. Pathological specimens retrieved from the archives were included in this study. We collected information on the following parameters: FIGO clinical stage, age, histological type, grade of differentiation, tumour size, depth of cervical stromal invasion, LVSI, parametrial invasion, resection margin status, LN metastasis, adjuvant therapy, date of recurrence, location of recurrent disease, treatment at recurrence, and date of death or last follow-up.

Follow-up. The patients were periodically inspected every 3 months for the first 2 years, every 6 months for the following 3 years, and every 12 months thereafter. At the time of the examination, imaging studies, including magnetic resonance imaging or computed tomography and chest radiography, were conducted annually. When tumour recurrence was suspected based on the clinical findings or other imaging studies, biopsies on the suspected lesions were performed. We defined progression-free survival (PFS) as the last follow-up day or the time from the initial treatment to relapse, and overall survival (OS) as the last follow-up day or the time from the initial treatment to death from cervical cancer.

Statistical analysis. OS and PFS were assessed using the Kaplan-Meier method. Group comparison in the univariate analysis was performed using the log-rank test for categorical factors and a Cox proportional hazards model for continuous factors. All the prognostic factors identified as being significant in the univariate analysis were included in the multivariate analysis using a Cox proportional hazards model. Stepwise backward elimination methods were used to select the factors included in the multivariate Cox proportional hazards model (inclusion criteria, $\mathrm{P}<0.05$; exclusion criteria, $\mathrm{P}>0.1)$. Significance was defined as a P-value $<0.05$. Data analyses were performed using SPSS software for Windows, version 11.0 (SPSS Inc., Chicago, IL, USA).

\section{Results}

Patient characteristics. The clinicopathological characteristics of the patients are summarised in Table I. The mean age was 49 years (range, 29-75 years). A total of 141 patients had stage IB and 15 patients had stage IIA disease. A total of 123 patients had squamous cell carcinoma, 24 had adenocarcinoma and 9 patients were diagnosed with other histological types. The depth of stromal invasion was $<1 / 3$ in 32 patients, between $1 / 3$ and $2 / 3$ in 50 patients, and $\geq 2 / 3$ in 74 patients. The size of the
Table I. Patient characteristics.

\begin{tabular}{|c|c|}
\hline Characteristics & $\begin{array}{l}\text { Number of cases }(\%) \\
\qquad(\mathrm{n}=156)\end{array}$ \\
\hline \multicolumn{2}{|l|}{ Age, years } \\
\hline$<50$ & $78(50.0)$ \\
\hline$\geq 50$ & $78(50.0)$ \\
\hline \multicolumn{2}{|l|}{ FIGO stage } \\
\hline IB 1-IB2 & $141(90.4)$ \\
\hline IIA1-IIA2 & $15(9.6)$ \\
\hline \multicolumn{2}{|l|}{ Histological type } \\
\hline SCC & $123(78.8)$ \\
\hline Adenocarcinoma & $24(15.4)$ \\
\hline Others & $9(5.8)$ \\
\hline \multicolumn{2}{|c|}{ Depth of stromal invasion } \\
\hline$<1 / 3$ & $32(20.5)$ \\
\hline$\geq 1 / 3-<2 / 3$ & $50(32.1)$ \\
\hline$\geq 2 / 3$ & $74(47.4)$ \\
\hline \multicolumn{2}{|l|}{ Tumour size, $\mathrm{cm}$} \\
\hline$\leq 2$ & $64(41.0)$ \\
\hline $2-4$ & $67(43.0)$ \\
\hline$>4$ & $25(16.0)$ \\
\hline \multicolumn{2}{|l|}{ Parametrial invasion } \\
\hline Negative & $132(84.6)$ \\
\hline Positive & $24(15.4)$ \\
\hline \multicolumn{2}{|c|}{ Lymphovascular invasion } \\
\hline Negative & $60(38.5)$ \\
\hline Positive & $96(61.5)$ \\
\hline \multicolumn{2}{|l|}{ Resection margin } \\
\hline Negative & $141(90.4)$ \\
\hline Positive & $15(9.6)$ \\
\hline \multicolumn{2}{|c|}{ Lymph node metastasis } \\
\hline Negative & $129(82.7)$ \\
\hline Positive & $27(17.3)$ \\
\hline \multicolumn{2}{|c|}{ Number of positive nodes } \\
\hline 0 & $129(82.7)$ \\
\hline 1 & $14(9.0)$ \\
\hline$\geq 2$ & $13(8.3)$ \\
\hline \multicolumn{2}{|l|}{ Adjuvant treatment } \\
\hline None & $34(21.8)$ \\
\hline Radiation therapy & $54(34.6)$ \\
\hline CCRT & $68(43.6)$ \\
\hline
\end{tabular}

FIGO, International Federation of Gyneacology and Obstetrics; SCC, squamous cell carcinoma; CCRT, concurrent chemoradiotherapy.

tumour was $\leq 2 \mathrm{~cm}$ in 64 patients, $2-4 \mathrm{~cm}$ in 67 patients, and $>4 \mathrm{~cm}$ in 25 patients. Of the 156 patients, 24 had parametrial invasion, 96 had LVSI, 15 had positive resection margins, and 27 patients had LN metastasis. Of the 27 patients with LN metastasis, 14 had 1 positive node and $13 \mathrm{had} \geq 2$ positive nodes. A total of 68 patients received treatment with CCRT, 54 received RT alone, and 34 received no adjuvant therapy (Table I). 
Table II. Univariate analysis of clinicopathological factors.

\begin{tabular}{|c|c|c|c|c|}
\hline \multirow[b]{2}{*}{ Factors } & \multicolumn{2}{|c|}{ Progression-free survival } & \multicolumn{2}{|c|}{ Overall survival } \\
\hline & HR $(95 \% \mathrm{CI})$ & P-value & HR $(95 \% \mathrm{CI})$ & P-value \\
\hline $\begin{array}{l}\text { Age, years } \\
<50 \\
\geq 50\end{array}$ & $0.80(0.33-1.93)$ & 0.616 & $0.79(0.24-2.58)$ & 0.692 \\
\hline $\begin{array}{l}\text { FIGO stage } \\
\text { IB1-IB2 } \\
\text { IIA1-IIA2 }\end{array}$ & $4.47(1.71-11.65)$ & 0.002 & $8.53(2.60-28.01)$ & 0.001 \\
\hline $\begin{array}{l}\text { Histological type } \\
\text { SCC } \\
\text { Adenocarcinoma } \\
\text { Others }\end{array}$ & $1.90(0.68-5.33)$ & 0.224 & $2.08(0.54-8.07)$ & 0.287 \\
\hline $\begin{array}{l}\text { Depth of stromal invasion } \\
<1 / 3 \\
\geq 1 / 3-<2 / 3 \\
\geq 2 / 3\end{array}$ & $2.72(1.24-5.96)$ & 0.013 & $8.23(1.22-55.66)$ & 0.031 \\
\hline $\begin{array}{l}\text { Tumour size, cm } \\
\leq 2 \\
2-4 \\
>4\end{array}$ & $2.62(1.41-4.87)$ & 0.002 & $2.51(1.09-5.80)$ & 0.032 \\
\hline $\begin{array}{l}\text { Parametrial invasion } \\
\text { Negative } \\
\text { Positive }\end{array}$ & $1.31(0.44-3.91)$ & 0.634 & $2.00(0.53-7.54)$ & 0.307 \\
\hline $\begin{array}{l}\text { Lymphovascular invasion } \\
\text { Negative } \\
\text { Positive }\end{array}$ & $3.88(1.14-13.24)$ & 0.031 & $6.89(0.88-5.82)$ & 0.066 \\
\hline $\begin{array}{l}\text { Resection margin } \\
\text { Negative } \\
\text { Positive }\end{array}$ & $2.78(0.93-8.33)$ & 0.067 & $1.08(0.14-8.47)$ & 0.939 \\
\hline $\begin{array}{l}\text { Lymph node metastasis } \\
\text { Negative } \\
\text { Positive }\end{array}$ & $2.22(0.85-5.77)$ & 0.103 & $3.02(0.88-10.33)$ & 0.078 \\
\hline $\begin{array}{l}\text { Number of positive nodes } \\
0 \\
1 \\
\geq 2\end{array}$ & $2.02(1.17-3.50)$ & 0.012 & $2.61(1.32-5.13)$ & 0.006 \\
\hline $\begin{array}{l}\text { Adjuvant treatment } \\
\text { None } \\
\text { Radiation therapy } \\
\text { CCRT }\end{array}$ & $0.66(0.27-1.59)$ & 0.348 & $1.45(0.42-4.96)$ & 0.555 \\
\hline
\end{tabular}

HR, hazard ratio; CI, confidence interval; FIGO, International Federation of Gyneacology and Obstetrics; SCC, squamous cell carcinoma; CCRT, concurrent chemoradiotherapy.

The 5-year OS and PFS rates were 92.9 and 87.2\%, respectively. A total of 20 patients developed recurrence, including 8 patients with recurrence in the pelvis, 10 with recurrence at distant sites, and 2 with recurrence at local as well at distant sites. The most frequent sites in the pelvis were the vaginal stump $(n=6)$, followed by the pelvic sidewall $(n=2)$. The most frequent sites of distant metastases were the lung $(n=5)$, followed by the liver $(n=3)$, bone $(n=2)$, peritoneum $(n=1)$ and brain $(n=1)$. Of the 156 patients included in our analysis, 42 had a follow-up duration of $<60$ months, with 31 patients lost to follow-up for $>1$ year at the time of the analysis. The median follow-up duration of patients lost to follow-up was 29 months (range, 12-54 months). 
Table III. Mutivariate analysis of clinicopathological factors.

\begin{tabular}{|c|c|c|c|c|}
\hline \multirow[b]{2}{*}{ Factors } & \multicolumn{2}{|c|}{ Progression-free survival } & \multicolumn{2}{|c|}{ Overall survival } \\
\hline & $\mathrm{HR}(95 \% \mathrm{CI})$ & P-value & HR (95\% CI) & P-value \\
\hline $\begin{array}{l}\text { FIGO stage } \\
\text { IB1-IB2 } \\
\text { IIA1-IIA2 }\end{array}$ & $3.47(1.01-11.98)$ & 0.049 & $6.54(1.77-24.16)$ & 0.002 \\
\hline $\begin{array}{l}\text { Depth of stromal invasion } \\
<1 / 3 \\
\geq 1 / 3-<2 / 3 \\
\geq 2 / 3\end{array}$ & $1.53(0.66-3.55)$ & 0.317 & $4.15(0.64-27.04)$ & 0.158 \\
\hline $\begin{array}{l}\text { Tumour size } \\
\leq 2 \\
2-4 \\
>4\end{array}$ & $1.57(0.70-3.52)$ & 0.272 & $1.00(0.38-2.60)$ & 0.968 \\
\hline $\begin{array}{l}\text { Lymphovascular invasion } \\
\text { Negative } \\
\text { Positive }\end{array}$ & $2.61(0.71-9.67)$ & 0.15 & $5.62(0.64-48.97)$ & 0.118 \\
\hline $\begin{array}{l}\text { Resection margin } \\
\text { Negative } \\
\text { Positive }\end{array}$ & $0.87(0.21-3.58)$ & 0.85 & $0.20(0.02-1.80)$ & 0.15 \\
\hline $\begin{array}{l}\text { Number of positive nodes } \\
0 \\
1 \\
\geq 2\end{array}$ & $1.23(0.63-2.42)$ & 0.546 & $2.30(1.13-4.67)$ & 0.021 \\
\hline
\end{tabular}

HR, hazard ratio; CI, confidence interval; FIGO, International Federation of Gyneacology and Obstetrics.

Univariate analysis. The results of the univariate analysis of the prognostic factors are presented in Table II. In the log-rank test, tumour stage $(\mathrm{P}<0.001)$, stromal invasion $(\mathrm{P}=0.031)$, the size of the tumour $(\mathrm{P}=0.032)$ and the number of positive LNs $(\mathrm{P}=0.006)$ were identified as significant prognostic factors for OS, favouring a lower tumour stage, stromal invasion of $<2 / 3$, a tumour size of $<4 \mathrm{~cm}$ and a small number of positive LNs, respectively. Patients with metastatic LNs were stratified into two groups according to the number of positive LNs, with one group that had 1 positive node, and the other group that had $\geq 2$ positive nodes. The 5 -year OS rates for patients with 0,1 and $\geq 2$ positive nodes were 91,80 and $47 \%$, respectively $(\mathrm{P}=0.006)$. There was no evidence of an association between OS rates and age, histological type, parametrial invasion, LVSI, resection margin, $\mathrm{LN}$ metastasis, or type of adjuvant therapy.

Tumour stage $(\mathrm{P}=0.002)$, stromal invasion $(\mathrm{P}=0.013)$, and the number of positive LNs $(\mathrm{P}<0.012)$ were also identified as significant prognostic factors for PFS, favouring a lower tumour stage, stromal invasion of $<2 / 3$, and a small number of positive LNs, respectively.

Multivariate analysis. The results of the multivariate analysis of the prognostic factors are presented in Table III. The Cox proportional hazards model was used for the multivariate analysis. In terms of OS, tumour stage $(\mathrm{P}=0.002)$ and the number of positive LNs $(\mathrm{P}=0.021)$ were identified as significant prog- nostic factors. In terms of PFS, tumour stage $(\mathrm{P}=0.049)$ was identified as a significant prognostic factor.

\section{Discussion}

Management of early cervical cancer may include surgery or CCRT. Although LN status does not modify the FIGO clinical stage, when LN metastases are present, the 5-year survival rate has been shown to decrease from 85 to $50 \%$ (11). Therefore, LN status represents the most important prognostic factor, with the absence of LN metastasis predicting a better prognosis compared with histologically proven positive LNs.

Positive pelvic LNs are an important prognostic factor in cervical cancer (13). Regarding LN involvement, there is a positive association between the number of positive LNs and patient prognosis $(13,14)$. The 5-year OS rates for patients with 0,1 and $\geq 2$ positive pelvic nodes were reported to be 89,83 and $58 \%$, respectively $(\mathrm{P}=0.007)$. In our study on stage IB-IIA cervical cancer patients, the number of positive LNs was identified as a significant prognostic factor in terms of 5-year OS rates $(\mathrm{P}=0.021)$. Aoki et al (15) classified positive LN patients into three groups (low, intermediate and high-risk) according to the status of parametrial invasion and the number of positive LNs. The 5-year OS rates for the intermediate-risk group were significantly lower compared with those for the low-risk group, but were significantly higher compared with those for the high-risk group. 
The prognostic value of the number of positive LNs has yet to be determined. In cases where there is only 1 positive node, no adverse effect on patient survival has been observed, according to certain authors $(16,17)$. Inoue and Morita (14) reported on the effect of the number of positive LNs on stage IB-IIB cervical cancer. The 5-year OS rates for patients with $0,1,2-3$ and $\geq 4$ positive nodes were $89,81,41$ and $23 \%$, respectively. Sakuragi et al (18) have reported the cumulative 5 -year OS rates for patients with 1 and $\geq 2$ positive nodes to be 84.9 and $26.5 \%$, respectively, with no difference between cumulative OS rates of patients with 0 and those with 1 positive node.

The potential effect of chemotherapy treatment of cervical cancer has been reported in a number of phase II trials (19), in which cisplatin was shown to be the most effective chemotherapeutic agent (20). CCRT is considered more effective compared with RT alone in patients associated with high-risk factors following $\mathrm{RH}$. This was demonstrated in a randomised clinical trial of CCRT or RT alone in stage IA2-IIA cervical cancer patients. The 4-year OS rates were significantly increased in CCRT-treated patients (81\%) compared with those in patients treated with RT alone (71\%) (11). Green et al (21) reported that the advantages of CCRT over RT alone may be explained by a meta-analysis in which patients with FIGO clinical stage IB-IVA disease were randomly assigned to primary therapy with CCRT or RT alone, with or without surgery, and with or without additional adjuvant chemotherapy.

The major strength of our study is that all the participants were recruited from a single institution, ensuring uniform treatment guidelines and surgical expertise. The limitations include the retrospective design and the heterogeneity of the patient population. However, the study spans an 8-year period during which the treatment methods and therapeutic regimens have changed.

In this study, we found that the metastatic $\mathrm{LN}$ number was independently associated with poorer survival outcomes in patients with early cervical cancer (stage IB-IIA), who underwent type III RH with LN dissection, with or without adjuvant therapy. Future prospective studies are required, using large numbers of patients from multiple institutions.

\section{Acknowledgements}

The present study was supported by a research grant from Dong-A University.

\section{References}

1. Thun MJ, DeLancey JO, Center MM, Jemal A and Ward EM: The global burden of cancer: Priorities for prevention. Carcinogenesis 31: 100-110, 2010.

2. Suh DH, Kim JW, Aziz MF, Devi UK, Ngan HY, Nam JH, Kim SC, Kato T, Ryu HS, Fujii S, et al: Asian Society of Gynecologic Oncology Workshop 2010. J Gynecol Oncol 21: 137-150, 2010.

3. Pecorelli S: Revised FIGO staging for carcinoma of the vulva, cervix and endometrium. Int J Gynaecol Obstet 105: 103-104, 2009.
4. Boyce JG,Fruchter RG, Nicastri AD, DeRegt RH, Ambiavagar PC, Reinis M, Macasaet MA and Rotman M: Vascular invasion in stage I carcinoma of the cervix. Cancer 53: 1175-1180, 1984.

5. Zreik TG, Chambers JT and Chambers SK: Parametrial involvement, regardless of nodal status: A poor prognostic factor for cervical cancer. Obstet Gynecol 87: 741-746, 1996.

6. Delgado G, Bundy B, Zaino R, Sevin BU, Creasman WT and Major F: Prospective surgical-pathological study of disease-free interval in patients with stage IB squamous cell carcinoma of the cervix: A Gynecologic Oncology Group study. Gynecol Oncol 38: 352-357, 1990.

7. Sevin BU, Lu Y, Bloch DA, Nadji M, Koechl OR and Averette HE: Surgically defined prognostic parameters in patients with early cervical carcinoma. A multivariate survival tree analysis. Cancer 78: 1438-1446, 1996.

8. Kamura T, Tsukamoto N, Tsuruchi N, Saito T, Matsuyama T, Akazawa K and Nakano H: Multivariate analysis of the histopathologic prognostic factors of cervical cancer in patients undergoing radical hysterectomy. Cancer 69: 181-186, 1992.

9. Piver MS and Chung WS: Prognostic significance of cervical lesion size and pelvic node metastases in cervical carcinoma. Obstet Gynecol 46: 507-510, 1975.

10. Estape RE, Angioli R, Madrigal M, Janicek M, Gomez C, Penalver $\mathrm{M}$ and Averette $\mathrm{H}$ : Close vaginal margins as a prognostic factor after radical hysterectomy. Gynecol Oncol 68: 229-232, 1998.

11. Peters WA III, Liu PY, Barrett RJ II, Stock RJ, Monk BJ, Berek JS, Souhami L, Grigsby P, Gordon W Jr and Alberts DS: Concurrent chemotherapy and pelvic radiation therapy compared with pelvic radiation therapy alone as adjuvant therapy after radical surgery in high-risk early-stage cancer of the cervix. J Clin Oncol 18: 1606-1613, 2000.

12. Quinn MA, Benedet JL, Odicino F, Maisonneuve P, Beller U, Creasman WT, Heintz AP, Ngan HY and Pecorelli S: Carcinoma of the cervix uteri. FIGO 26th Annual Report on the Results of Treatment in Gynecological Cancer. Int J Gynaecol Obstet 95 (Suppl 1): S43-S103, 2006.

13. Uno T, Ito H, Itami J, Yasuda S, Isobe $\mathrm{K}$, Hara R, Sato $\mathrm{T}$, Minoura S, Shigematsu N and Kubo A: Postoperative radiation therapy for stage IB-IIB carcinoma of the cervix with poor prognostic factors. Anticancer Res 20: 2235-2239, 2000.

14. Inoue $\mathrm{T}$ and Morita $\mathrm{K}$ : The prognostic significance of number of positive nodes in cervical carcinoma stages IB, IIA and IIB. Cancer 65: 1923-1927, 1990.

15. Aoki Y, Sasaki M, Watanabe M, Sato T, Tsuneki I, Aida H and Tanaka K: High-risk group in node-positive patients with stage IB, IIA and IIB cervical carcinoma after radical hysterectomy and postoperative pelvic irradiation. Gynecol Oncol 77: 305-309, 2000.

16. Lai CH, Chang HC, Chang TC, Hsueh S and Tang SG: Prognostic factors and impacts of adjuvant therapy in early-stage cervical carcinoma with pelvic node metastases. Gynecol Oncol 51: 390-396, 1993.

17. Park TK, Kwon JY, Kim SW, Kim SH, Kim SN and Kim GE: Patterns of treatment failure following radiotherapy with combination chemotherapy for patients with high-risk stage IIB cervical carcinoma. Int J Clin Oncol 9: 120-124, 2004.

18. Sakuragi N, Satoh C, Takeda N, Hareyama H, Takeda M, Yamamoto R, Fujimoto T, Oikawa M, Fujino T and Fujimoto S: Incidence and distribution pattern of pelvic and paraaortic lymph node metastasis in patients with stages IB, IIA and IIB cervical carcinoma treated with radical hysterectomy. Cancer 85: 1547-1554, 1999

19. Bonomi P, Blessing J, Ball H, Hanjani P and DiSaia PJ: A phase II evaluation of cisplatin and 5-fluorouracil in patients with advanced squamous cell carcinoma of the cervix: A Gynecologic Oncology Group study. Gynecol Oncol 34: 357-359, 1989.

20. Omura GA: Chemotherapy for stage IVB or recurrent cancer of the uterine cervix. J Natl Cancer Inst Monogr: 123-126, 1996.

21. Green JA, Kirwan JM, Tierney JF, Symonds P, Fresco L, Collingwood $\mathrm{M}$ and Williams CJ: Survival and recurrence after concomitant chemotherapy and radiotherapy for cancer of the uterine cervix: A systematic review and meta-analysis. Lancet 358: 781-786, 2001. 